\title{
The evolution of human communication
}

\author{
Herman Yeger
}

Received: 12 February 2015 / Accepted: 13 February 2015 /Published online: 25 February 2015

(C) The International CCN Society 2015

We have all likely displayed wonderment on how human communications have evolved from a rather primitive, and likely effective for the time period, cave drawings, to a myriad of languages, and then to our present day highly sophisticated internet modalities. One might even say that YouTube is a greatly enhanced and accelerated cave drawing with sound. Our command of electronic communication and interactive devices has thus far gone from finger control to voice command. In the article, "Knock Once For YES, Twice For No", Professor Bernard Perbal has enticed our neural centers with the possibility of conscious brain-to-brain communication, in wireless mode. If able to be accomplished in the future he writes that the 'wide use of such applications might seem a long way off, they raise quite a number of ethical, legal and societal issues'. Professor Perbal, a long time proponent of the individual's rights to their own genetic information, the essentiality of freedom of speech, and the importance of communication, has laid out some very thoughtful arguments, and provided some fascinating experimental evidence for why brain-to-brain communication should be seriously entertained. After all, if brain is the last frontier in our research endeavors, then communications between brains,

\section{H. Yeger $(\bowtie)$}

Department of Paediatric Laboratory Medicine, The Hospital for Sick Children, 555 University Ave, Toronto, Ontario M5G 1X8, Canada

e-mail: hermie@sickkids.ca

H. Yeger

Program in Developmental \& Stem Cell Biology, Peter Gilgan Cente for Research and Learning, 686 Bay St, Toronto, Ontario M5G 0A4, Canada in all its variations, should be one area of research that is highly warranted. As indicated large scale international consortia are busy mapping out the brain circuitry in the hope, like genomics, that once we have all the coordinates and molecular details we will be able to understand our incredible 'brainy' supercomputer and treat illnesses with precision. However, in the same way genetics has now been confounded by epigenetics, non-coding DNA, and RNA bits and bytes, we might expect that the basic brain map may be confounded by yet, undefined circuits and unexplained phenomena, like telepathy. As another example of how original conceptions have been thrown out the window comes from the field of sensory perception. One could now say that our bodies are one incredible taste and odorant sensor (Foster et al. 2014).

So can brain-to-brain communications stand on their own or, as many of you know from everyday experiences, the visual (even using past memories) is an essential element for total comfort with your communicator (Perrodin et al. 2015). And, while you are busy reading this online please note the following (Kuhn and Gallinat 2015).

The journey into the future new world of brain-to-brain communication will be with some trepidation. In comparison to information transmission through the ether, we can all appreciate current practical applications such as controlling prosthetic limbs by integration of the nervous system, a truly fantastic advance. There is no doubt, as Professor Perbal states that mind over matter, machines, and other brains, would have enormous implications for us and the world. Communication with animals could bring a whole new meaning to 'man's best friend'. Once we really open up this Pandora's Box then we have to be prepared to use our collective wisdom to avoid possible abuse and misuse. 


\section{References}

Foster SR, Roura E, Thomas WG (2014) Extrasensory perception: odorant and taste receptors beyond the nose and mouth. Pharmacol Ther $142: 41-61$
Kuhn S, Gallinat J (2015) Brains online: structural and functional correlates of habitual internet use. Addict Biol 20:415-22

Perrodin C, Kayser C, Logothetis NK, Petkov CI (2015) Natyral asychronies in audiovisual communication sugnals regulate neuronal multisensory interactions in voice-sensitive cortex. Proc Natl Acad Sci U S A 112:273-8 